Tacken, M., Braspenning, J., Spreeuwenberg, P., Hoogen, H. van den, Essen, G. van, Bakker, D. de, Grol, R. Patient characteristics determine differences in the influenza vaccination rate more so than practice features. Preventive Medicine: 35, 2002, nr. 4, p. 401-406

\begin{tabular}{|l|l|}
\hline Postprint Version & 1.0 \\
\hline Journal website & $\underline{\mathrm{http} / / \mathrm{www} \cdot \text { sciencedirect.com/ }}$ \\
\hline $\begin{array}{l}\text { Pubmed link } \\
\text { DOI }\end{array}$ & $\underline{\text { http://www.ncbi.nlm.nih.gov/pubmed/12453719 }}$ \\
\hline$\underline{10.1006 / \mathrm{pmed} .2002 .1083}$
\end{tabular}

\title{
Patient Characteristics Determine Differences in the Influenza Vaccination Rate More so Than Practice Features $^{1}$
}

Margot Tacken, M.Sc., ${ }^{* 2}$ Joze' Braspenning, Ph.D., ${ }^{\prime}$ Peter Spreeuwenberg, M.A., ${ }^{\dagger}$ Henk Van

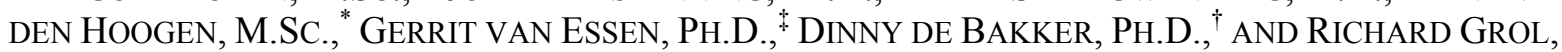
PH.D.*

* entre for Quality of Care Research, University of Nijmegen/University of Maastricht, The Netherlands; † etherlands Institute of Primary Health Care (NIVEL), The Netherlands;

$\ddagger$ ulius Center for Health Sciences and Primary Care, University Medical Center Utrecht, The Netherlands

Background. World-wide each year $30-55 \%$ of the target population is vaccinated against influenza. Determinants of successful vaccination programs are not clear. This study was aimed at identifying practiceand patient-related factors that determine differences in vaccination rates.

Methods. Data on patients of the target population were extracted from the computerized medical record systems of 48 family practices. Information about organizational factors was collected by a questionnaire for GP's. Multilevel logistic regression analyses were used to assess the determinants.

Results. Of all patients at risk $(42,426), 76 \%$ were vaccinated. The vaccination rate for patients above age 65 was $15 \%$ higher when a medical indication was present. Patients with cardiac diseases or diabetes mellitus attained a relatively higher vaccination rate than other groups at risk. Special hours for vaccination led to significantly higher vaccination rates for the elderly and cardiac patients. Patients below 65 years of age were particularly influenced by special information pamphlets.

Conclusion. Explanations of differences in uptake rates were found at the patient level. All practices in this study were well organized; nevertheless, subgroup analyses showed that special vaccination hours for elderly people and information pamphlets for young people could improve results further.

\section{INTRODUCTION}

Influenza, an acute respiratory illness with a high morbidity and significant mortality that occurs in epidemic proportions almost every winter, is a threat to public health, especially for patients with comorbidities [1-4]. Most influenza vaccination programs are targeted at citizens aged 65 years or older

1 This study was supported financially by the College voor zorgverzekeringen (CVZ) ["Health Care Insurance Board"].

2 To whom correspondence and reprint requests should be addressed at Centre for Quality of Care Research, University of Nijmegen, PO Box 9101, NL-6500 HB Nijmegen, The Netherlands. Fax:_31 24 3540166. E-mail: M.Tacken@HSV.KUN.NL. 
Tacken, M., Braspenning, J., Spreeuwenberg, P., Hoogen, H. van den, Essen, G. van, Bakker, D., Grol, R. Patient characteristics determine differences in the influenza vaccination rate more so than practice features. Preventive Medicine: 35, 2002, nr. 4, p. 401-406

or those with high-risk conditions [3,5-9]. Worldwide, the influenza vaccination rate remains low; overall, studies show that only about $30-55 \%$ of the target population is vaccinated [10-12].

Several studies have sought to explain differences in vaccination rates. Vaccination rates were found to be higher in urban practices [13] and lower in group practices [14]. Population-based prevention, such as influenza vaccination requires organized approaches of the general practices for inviting, reminding, and monitoring patients. Good organization enhances the vaccination rate [14-19]. Patient characteristics, such as age, gender, and type of health insurance, are also qualified determinants $[15,20,21]$.

Between 1991 and 1996, there was a marked increase in the Netherlands in the influenza vaccination rate for high-risk patients (28\% in 1991 and $48 \%$ in 1996) [22]. In the following years, a national health promotion campaign to enhance a population-based approach toward influenza vaccination was launched with a fee-for-service for family doctors and software for family practices to support their organization (computerized search for selecting risk groups, inviting all selected patients, and reminding the nonrespondents). The influenza vaccination is free of charge for all the Netherlands high-risk patients. A standard protocol surely reduces practice-based variation. However, practices may undertake supplementary activities, such as arranging special designated hours for vaccination, distributing information pamphlets, or reminding high-risk patients.

Specific risk groups may respond differently to the various practice procedures. Vaccination rates are known to vary among different patient groups [23], and flu shot acceptance is related to older age [24]. Diabetics, who visit their family doctors frequently, have a higher vaccination rate than patients with mildly serious pulmonary diseases. Patients at risk often belong to more than one risk group, thereby increasing their risk. Moderate-risk groups have a relatively lower vaccination rate than high-risk groups [25].

To our knowledge, there is no previous research about the relationship between determinants at practice and patient levels, or about the specificity of determinants for particular risk groups. The questions addressed were: At which level can the strongest determinants be expected? Do established determinants fade away and others emerge, because cluster contamination was never taken into account? This article reports information about the vaccination rate in the Netherlands in 1999 and the determinants at practice and patient levels. Knowledge of the determinants can indicate how procedures may be further improved.

\section{METHODS}

\section{Study Population and Setting}

The research network for influenza vaccination rate monitoring consisted of 56 family practices, all are linked through a network of computerized family practices [National Information Network in Family Practices (LINH)] and use a computerized medical record system (CMRS). The family doctors in these practices included all of their high-risk patients for immunization in conformance with the "Dutch College of General Practitioners" immunization guidelines [26]. Designated patients were registered by an influenza indication tag in the CMRS.

\section{Procedure and Data Collection}

The routinely collected data were extracted from the CMRS with specially developed software. The data were collected at the patient level, because measurements at patient and at (aggregated) practice level were sought. The data included age, gender, type of health insurance (social health insurance or private health insurance), risk group, the influenza indication tag, and whether vaccination had been given. Information about organizational factors was collected by questionnaire. Data on practice type and urbanization level were derived from the regular data collection within the network.

\section{Analyses}

Descriptive statistics were used to compare practice characteristics and population characteristics within the national data. Descriptive statistics were also used to describe the population studied. Vaccination rates at the patient level were calculated for the total group of high-risk patients and for the different groups at risk. The patients aged 65 years or older were dichotomized into groups with and without any medical indication(s) other than their age. Aggregation of the data at practice level facilitated the calculation of the vaccination rates of the individual family practices. The relative rate of vaccination of the population in any given practice was calculated by rating all vaccinations against the number of patients in all of the practices. 
Tacken, M., Braspenning, J., Spreeuwenberg, P., Hoogen, H. van den, Essen, G. van, Bakker, D., Grol, R. Patient characteristics determine differences in the influenza vaccination rate more so than practice features. Preventive Medicine: 35, 2002, nr. 4, p. 401-406

Multilevel logistic regression modeling was considered the most appropriate technique for separating determinants at practice and patient levels in one analysis. We accounted for the clustering effect of patients that are nested within the practice and the varying number on patients between the practices (unbalanced data) [27]. Thus, multilevel logistic regression analyses were used to assess whether patients were immunized. The dependent variable in the model was whether the patient had been immunized or not. Twelve independent variables were included in the optimal model: six at practice level, six at patient level. Three of the items at practice level were demographic: "practice setting"; "urban area"; "the list size (number of patients) per full-time equivalent family doctor in the practice." The other three items were organizational, namely "reminding nonresponding high-risk patients," "use of pamphlets," and "offering special hours for vaccination."

The six items included at the patient level were: "age"; "gender"; "health insurance type" (social health insurance or private health insurance); three conditions (diabetic, cardiac, pulmonary diseases). Separate analyses with the optimal model were applied to subgroups of patients at risk to examine whether the determinants were specific to a risk group: These groups of patients comprised those: aged 65 years and older $(65+)$; below 65 years of age $(<65)$; with diabetic diseases; with cardiac diseases; with pulmonary diseases. Most of the patients with pulmonary diseases were below 65 years of age; therefore, the model was also applied to the selected patients with pulmonary diseases who were less than 65 years old. The influence of continuous variables was analyzed with increasing steps of one standard deviation compared with the mean [28]. The mean and standard deviation used for comparison were calculated separately for each subgroup. The likelihood of the dependent variable is presented in odds ratios (ORs) while controlling for the other variables in the model, with $95 \%$ confidence intervals $(95 \mathrm{CI})$. The significance level was $P<0.05$. The proportion of variance explained $\left(\mathrm{R}^{2}\right)$ by the significant variables in our model was estimated by using the McKelvey and Zavoina definition adapted to multilevel logistic regression models as described by Snijders and Bosker [27].

\section{RESULTS}

\section{Study Population}

After checking the extracted data, 48 out of 56 practices (86\%) were included in the analyses. Eight practices had to be excluded because they used registration methods that could not be translated into useful data. The patient study population represented the Netherlands population at large, but there was an underrepresentation of solo practices and practices in large cities (see Table 1).

\section{[ TABLE 1 ]}

\section{Patients at Risk and Vaccination Rates}

Of the total practice population, $16.3 \%$ were vaccinated. Altogether, 42,426 patients were at risk; that is $21.3 \%$ of the total population in the practices surveyed. Of all patients at risk, $76 \%$ were actually vaccinated. The mean vaccination rate in the 48 practices was $76.3 \%$ (with a standard deviation of $7.1 \%$ ).

Table 2 shows the vaccination rates for the various high-risk groups of patients. It was about $15 \%$ higher for patients who had a second indication for vaccination in addition to their age $(\geq 65)$. The vaccination rate of patients with cardiac diseases or diabetes mellitus was relatively higher than that of the other groups at risk. The lowest vaccination rate was for patients with chronic staphylococcal infections $(69 \%)$. The vaccination rate of all high-risk patients before 65 years of age was $70 \%$.

\section{[ TABLE 2 ]}

\section{Determinants}

The items and their characteristics finally included in the optimal model are presented in Table 3. Most practices (96\%) offered special hours for vaccination. The mean age of the population at risk was 59.8 (SD 21.6) years; there were more women at risk, and as expected, more patients had social health insurance than private insurance (see Table 3 ). 
Tacken, M., Braspenning, J., Spreeuwenberg, P., Hoogen, H. van den, Essen, G. van, Bakker, D., Grol, R. Patient characteristics determine differences in the influenza vaccination rate more so than practice features. Preventive Medicine: 35, 2002, nr. 4, p. 401-406

\section{[ TABLE 3 ]}

The intra-class correlation (ICC) of the total population at risk was $1.89 \%$. That is to say, $1.89 \%$ of the vaccination rate can be attributed to differences between practices and about $98 \%$ can be attributed to differences between individual at-risk-patients. Table 4 presents an overview of the significant contributions of the items in the model.

\section{[ TABLE 4 ]}

Analysis of the defined subsets of individual highrisk patients revealed the level of urbanization to be a strong predictor of vaccination rate. The chance of being vaccinated was higher for those visiting practices in rural areas. No significant relationships were found between practice setting and the list size per full-time equivalent family doctor and vaccination rates.

Offering special hours for vaccination significantly improved vaccination rates for older patients and all cardiac patients (Fig. 1). Patients below 65 years of age were the only group influenced by special information pamphlets. Sending reminders was not a predictor for the level of the vaccination rate, except for some young patients. That is, in practices where nonresponders were reminded, the response rate of younger people was lower.

\section{[ FIGURE 1 ]}

The patient characteristics "age" and "health insurance type" yielded significant effects for all the subgroups. Vaccination rates increased with age (one standard deviation of the mean of each subgroup). Social health insurance patients have a significantly higher chance of being vaccinated than privately insured patients. The "gender" of patients was significant for all high-risk group patients, except those above 65 years, or those with cardiac diseases. Women had a significantly higher chance of being vaccinated than men. With some exceptions, a combination of different highrisk indicators increased the chance of being vaccinated significantly. One exceptional group was pulmonary patients with diabetes and below 65 years of age.

\section{DISCUSSION}

We examined determinants of the influenza vaccination rate, in particular practice- and patient-related factors influencing vaccination. There was an underrepresentation of solo practices and of practices in large cities. However, the vaccination rate was found to be representative of the Netherlands situation. Our vaccination rate of the total population was comparable (16.3 vs $16.4 \%)$ to the national vaccination rate based on data about the vaccine delivery [available from the "National Program Influenza Prevention Foundation" (SNPG)].

In $1999,76 \%$ of all patients at risk were actually vaccinated. Compared with the $48 \%$ vaccination rate of high-risk patients in 1996 [22], this was a large increase. Applying the logistic regression model, most of the variance could be attributed to differences between individual patients at risk (ICC 1.89). As expected, we found that patients with a moderate risk had a relatively lower vaccination rate than patients with a highrisk from influenza and its complications. Membership in more than one risk group enhanced the chance of vaccination, with the exception of diabetic patients also having a pulmonary disease. Patients suffering from diabetes probably experience more health problems related to their diabetes than to additional pulmonary problems.

Most of the practices offered special hours for vaccination only; there were two practices in our study not using them. These practices had a relatively low vaccination rate (mean $56.2 \%$ ), so the special hours raised the vaccination rate. Especially older patients and cardiac patients (relatively older) benefited the most from this facility. Specially designated vaccination clinics are usually organized during working hours and younger people might find compliance more difficult.

In contrast to previous research [13], our analysis of the defined subsets of high-risk patients revealed a greater chance of being vaccinated for practices situated in rural areas. In the Netherlands, health care vaccinations are carried out in small family practices spread over the country, while in other countries (USA, for example), a centralized approach is used. The influenza vaccinations are mostly done in 
Tacken, M., Braspenning, J., Spreeuwenberg, P., Hoogen, H. van den, Essen, G. van, Bakker, D., Grol, R. Patient characteristics determine differences in the influenza vaccination rate more so than practice features. Preventive Medicine: 35, 2002, nr. 4, p. 401-406

primary care internal medicine or in family medicine practices. For (older) people who live in rural areas, travelling to a health center can be difficult due to transportation problems.

Patients below 65 years of age were the only group influenced by special information pamphlets. Krieger and colleagues [29] found the greatest effect of mailing information (followed by tracking and outreach by senior volunteers) among participants who had not received a vaccination in the previous year. Both the outcome of our study and that of the Krieger study suggested that pamphlets mainly influence young and new risk patients, respectively. Most older people are probably aware that they should be vaccinated without receiving pamphlet information, while younger people may not know that their condition may be a high-risk indication for influenza complications.

The lack of any positive effect from reminding young patients may seem strange. Reminders ought to be effective, especially in practices with a relatively low vaccination rate. However, the low response rate of young patients in practices where nonresponding patients were reminded is in large part due to the fact that only practices with a low initial response rate had chosen to remind the patients. This reminder was not effective enough to make up a major impact.

Unfortunately, we have no markers for SES (socioeconomic status) in our database by now.

Nevertheless, we don't think that the lack of these SES markers could be an account for an effect on the variation we found. In a former Dutch study, no relation was found to influenza immunization compliance from socioeconomic variables [20].

The standardization of the administrative protocol for the execution of the influenza vaccination campaign and the overall high rates (76\%) seems to yield less improvement at practice level than might be expected. We were nevertheless able to identify determinants capable of improving the vaccination rates for the various groups at risk. Some determinants are indeed specific to particular high-risk groups; the significant influence of a separate vaccination hour for elderly people and the use of special information pamphlets for young people exemplify this. Exploitation of these actions for specific highrisk groups could increase the vaccination rate.

However, the most important message is that we have good evidence that, in other countries, high rates are achievable for large populations by changing basic organizational factors like use of special hours, pamphlets, and reminders.

\section{ACKNOWLEDGMENTS}

We thank all the members of the practices (family doctors and practice assistants) of the National Information Network in Family Practices (LINH) for their support.

\section{REFERENCES}

1. van Essen GA, Kuyvenhoven MM, de Melker RA. Implementing the Dutch College of General Practitioners' guidelines for influenza vaccination: an intervention study. $\mathrm{Br} J$ Gen Pract 1997; 47:259.

2. Nichol KL, Wuorenma J, von Sternberg T. Benefits of Influenza vaccination for low-intermediate-, and high risk citizens. Arch Intern Med 1998;158:1769-76.

3. Nichol KL, Margolis KL, Wuorenma J, von Sternberg T. Effectiveness of influenza vaccine in the elderly. Gerontology 1996; 42:274-9.

4. Nichol KL, Goodman M. The health and economic benefits of influenza vaccination for healthy and at-risk persons aged 65 to 74 years. Pharmacoeconomics 1999;16(suppl. 1):63-71.

5. Ahmed AE, Nicholson KG, Nguyen van Tam J. Reduction in mortality associated with influenza vaccine during 1989-90 epidemic. Lancet 1995;346:591-5.

6. Innes A, Beresford E, Bedford J. Influenza vaccination in asthma: a primary care experience. $\mathrm{Br} \mathrm{J}$ Gen Pract 2000;50:27-30.

7. Nichol KL, Margolis KL, Wuorenma J, von Sternberg T. The efficacy and cost effectiveness of vaccination against influenza among elderly persons living in the community. $\mathrm{N}$ Engl J Med 1994;331:778-84.

8. Govaert TME, Thijs CTM, Masurel N, Sprenger MJW, Dinant GJ, Knotnerus JA. The efficacy of influenza vaccination in elderly individuals. A randomized double-blind placebo-controlled trial. J Am Med Assoc 1994;272:1661-5.

9. Cifu A, Levinson W. Linking evidence and experience; influenza. J Am Med Assoc 2000;284:2847-9.

10. Beguin C, Boland B, Ninane J. Health care workers: vectors of influenza virus? Low vaccination rate among hospital health care workers. Am J Med Qual 1998;13:223-7. 
Tacken, M., Braspenning, J., Spreeuwenberg, P., Hoogen, H. van den, Essen, G. van, Bakker, D., Grol, R. Patient characteristics determine differences in the influenza vaccination rate more so than practice features. Preventive Medicine: 35, 2002, nr. 4, p. 401-406

11. Nexoe J, Kragstrup J, Soegaard J. Decision on influenza vaccination among the elderly; a questionnaire study based on the Health Belief Model and the multidimensional Locus of Control Theory. Scand J Prim Health Care 1999;17:105-10.

12. Zimmerman RK, Ruben FL, Ahwesh ER. Influenza, Influenza Vaccine, and Amantadine/Rimantadine. J Fam Pract 1997;45: 107-22.

13. Millar JS, Scheffler SA, Murray CK, Bratzler DW. Comparison of influenza immunization rates for Oklahoma Medicare patients: 1995, 1996 and 1997. J Okla State Med Assoc 1998;91:509-13.

14. Hak E, Hermens RPMG, van Essen GA, Kuyvenhoven MM, de Melker RA. Population-based prevention of influenza in Dutch general practice. Br J Gen Pract 1997;47:363-6.

15. Smith DM, Zhou XH, Weinberger M, Smith F, McDonald RC. Mailed reminders for area-wide influenza vaccination: a randomized controlled trial. J Am Geriatr Soc 1999;47:1-5.

16. McDowel I, Newell C, Rosser W. Comparison of three methods of recalling patients for influenza vaccination. CMAJ 1986;135: 991-7.

17. Brimberry R. Vaccination of high-risk patients for influenza: a comparison of telephone and mail reminder methods. J Fam Pract 1988;26:397-400.

18. Nichol KL. Long-term success with the National Health objective for influenza vaccination: an institution-wide model. J Gen Intern Med 1992;7:595-600.

19. Tang PC, LaRosa MP, Newcomb C, Gorden SM. Measuring the effects of reminders for outpatient influenza immunizations at the point of clinical opportunity. J Am Med Inform Assoc 1999; 6:115-21.

20. van Essen GA, Kuyvenhoven MM, de Melker RA. Compliance with influenza vaccination. Its relation with epidemiologic and sociopsychological factors. Arch Fam Med 1997;6:157-63.

21. McKinley JB, Potter DA, Feldman HA. Non-medical influences on medical decision-making. Soc Sci Med 1996;42:769-76.

22. van Essen GA, Bos JK. Griepvaccinatie sterk verbeterd. [Influenza vaccination strongly increased] Infectieziekten Bulletin 1997;8:163-6.

23. Hak E, van Essen GA, Stalman W, de Melker R. Improving influenza vaccination coverage among high-risk patients: a role for computer-supported prevention strategy? Fam Pract 1998; 15:138-43.

24. Chapman GB, Coups EJ. Predictors of influenza vaccine acceptance among healthy adults. Prev Med 1999;29:249-62, doi: 10.1006/pmed.1999.0535.

25. Gillick MR, Ditzion B. Influenza vaccination; are we doing better than we think? Arch Intern Med 1991;151:1742-4.

26. van Essen GA, Sorgedrager YCG, Salemink GW, Govaert ThME, van den Hoogen JPH, van der Laan JR. NHG-standaard influenza en influenzavaccinatie. ["Dutch College of General Practitioners" guideline, influenza and influenza vaccination] Huisarts Wet 1993;36:342-6 (with summary in English).

27. Snijders TAB, Bosker RJ. Multilevel analysis: an introduction to basic and advanced multilevel modelling. London: Sage 1999, pp. 225-7.

28. Hosmer DW, Lemeshow S. Applied logistic regression. New York: Wiley, 1989.

29. Krieger JW, Castorina JS, Walss ML, Weaver MR, Ciske S. Increasing Influenza and Pneumococcal immunization rates: a randomized controlled study of a senior center-based intervention. Am J Prev Med 2000;18:123-31.

\section{TABLES}

TABLE 1a

Practice Characteristics of the Study Population in Comparison with All Family Practices in the Netherlands

\begin{tabular}{|c|c|c|c|c|}
\hline & \multicolumn{2}{|c|}{$\begin{array}{c}\text { Study } \\
\text { population } \\
n=48 \\
\text { practices }\end{array}$} & \multicolumn{2}{|c|}{$\begin{array}{c}\text { All Netherlands } \\
\text { Family Practices } \\
\begin{array}{c}{ }^{a}=4,813 \\
\text { practices }\end{array}\end{array}$} \\
\hline & $n$ & $\%$ & $N$ & $\%$ \\
\hline \multicolumn{5}{|l|}{ Practice setting } \\
\hline 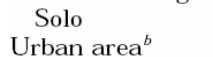 & 27 & 56.3 & 3,195 & 66.5 \\
\hline \multicolumn{5}{|l|}{ Urban $\operatorname{area}^{b}$} \\
\hline 1. Large city & 17 & 35.4 & 1,989 & 41.4 \\
\hline 2. Small urban & 21 & 43.8 & 1,982 & 41.3 \\
\hline 3. Rural area & 10 & 20.8 & 832 & 17.3 \\
\hline
\end{tabular}

TABLE 1b

Patient Characteristics of the Study Population in Comparison with All Inhabitants in the Netherlands

\begin{tabular}{lcc}
\hline & $\begin{array}{c}\text { Study population } \\
n=198,974 \\
\%\end{array}$ & $\begin{array}{c}\text { Netherlands population } \\
N=15,760,225 \\
\%\end{array}$ \\
\hline Age & & \\
$<15$ years & 19 & 19 \\
$15-44$ years & 43 & 44 \\
$45-64$ years & 25 & 24 \\
$\quad \begin{array}{c}25 \text { years } \\
\text { Gender } \\
\quad \text { Male }\end{array}$ & 13 & 14 \\
$\begin{array}{c}\text { Health insurance } \\
\text { Social health } \\
\text { insurance }\end{array}$ & 49 & 49 \\
\hline
\end{tabular}

${ }^{a}$ Source: CBS: 1-1-1999. 
Tacken, M., Braspenning, J., Spreeuwenberg, P., Hoogen, H. van den, Essen, G. van, Bakker, D., Grol, R. Patient characteristics determine differences in the influenza vaccination rate more so than practice features. Preventive Medicine: 35, 2002, nr. 4, p. 401-406

\section{TABLE 2}

Vaccination Rate of Patients at Risk According to High-Risk Indication

\begin{tabular}{lc}
\hline \multicolumn{1}{c}{ High-risk indication } & Vaccination rate (\%) \\
\hline Pulmonary disease & 75 \\
Cardiac disease & 86 \\
Diabetic Disease & 85 \\
Chronic renal insufficiency & 79 \\
Chronic staphylococcal infections & 69 \\
Age $\geq 65$ years & 81 \\
With extra high-risk & 87 \\
Without extra high-risk & 72 \\
High-risk but age $<65$ years & 70 \\
\hline
\end{tabular}

Note. Patients may belong to more than one high-risk group.

\begin{tabular}{|l|}
\hline Main findings of the study \\
* In well organized practices the vaccination rate among the elderly is $81 \%$ \\
versus $70 \%$ among the people at risk who are below 65 years of age. \\
* Special vaccination hours for the elderly can increase the vaccination rate. \\
* Information pamphlets enhance the vaccination rate among people at risk who \\
are younger than 65 years by $>50 \%$.
\end{tabular}

FIGURE 1

\section{TABLE 3}

Practice and Patient Characteristics of the Study Population as Used in the Multilevel Analyses (Number of Cases and Percentages)

\begin{tabular}{|c|c|}
\hline Practice characteristics & $N(\%)$ \\
\hline \multicolumn{2}{|l|}{ 1. Practice setting } \\
\hline Solo & $27(56.3)$ \\
\hline Group $^{a}$ & $21(43.7)$ \\
\hline \multicolumn{2}{|l|}{ 2. Urban area } \\
\hline Large city & $17(35.4)$ \\
\hline Small urban & $21(43.8)$ \\
\hline Rural area $^{a}$ & $10(20.8)$ \\
\hline \multicolumn{2}{|l|}{ 3. List size (patients) per fte family doctor } \\
\hline (mean, sd) & $2,544(367)$ \\
\hline \multicolumn{2}{|l|}{ 4. Reminder } \\
\hline Always & $5(10.4)$ \\
\hline Sometimes & $24(50.0)$ \\
\hline Never $^{a}$ & $19(39.5)$ \\
\hline \multicolumn{2}{|l|}{ 5. Use of pamphlets } \\
\hline Yes (with invitation or in waiting room) & $37(77.1)$ \\
\hline No use of information pamphlets ${ }^{a}$ & $11(22.9)$ \\
\hline \multicolumn{2}{|l|}{ 6. Hours for vaccination only } \\
\hline Yes & $46(95.8)$ \\
\hline $\mathrm{No}^{a}$ & $2(4.2)$ \\
\hline Patient characteristics & $N=42,025$ \\
\hline 7. Age (mean, SD) & $59.8(21.6)$ \\
\hline \multicolumn{2}{|l|}{ 8. Gender (\%) } \\
\hline Men & 45.8 \\
\hline Women $^{a}$ & 54.2 \\
\hline \multicolumn{2}{|l|}{ 9. Health insurance (\%) } \\
\hline Social health insurance & 70.7 \\
\hline Private health insurance $^{a}$ & 29.3 \\
\hline 10. Pulmonary disease & $n=12,913$ \\
\hline 11. Cardiac disease & $n=9,429$ \\
\hline 12. Diabetic disease & $n=5,160$ \\
\hline
\end{tabular}

TABLE 4

Relationship between Practice and Patient Characteristics with the Dependent Variable Vaccinated or Not $(P<0.05)$ (Significant Odds Ratios with Accompanying 95\% CI Are Presented)

\begin{tabular}{|c|c|c|c|c|c|c|}
\hline & $\begin{array}{c}65+ \\
(n=24,612)\end{array}$ & $\begin{array}{c}<65 \\
(n=17,413)\end{array}$ & $\begin{array}{l}\text { Diabetic disease } \\
\quad(n=5,160)\end{array}$ & $\begin{array}{l}\text { Cardiac disease } \\
(n=9,429)\end{array}$ & $\begin{array}{c}\text { Pulmonary } \\
\text { disease } \\
(n=12,913)\end{array}$ & $\begin{array}{l}\text { Pulmonary } \\
\text { disease }<65 \\
(n=9,030)\end{array}$ \\
\hline $\mathrm{R}^{2}$ & $\begin{array}{c}10.50 \\
\text { OR }(95 \mathrm{CI})\end{array}$ & $\begin{array}{c}8.44 \\
\text { OR }(95 \mathrm{CI})\end{array}$ & $\begin{array}{c}10.84 \\
\text { OR }(95 \mathrm{CI})\end{array}$ & $\begin{array}{c}10.82 \\
\text { OR }(95 \mathrm{CI})\end{array}$ & $\begin{array}{c}17.04 \\
\text { OR }(95 \mathrm{CI})\end{array}$ & $\begin{array}{c}8.34 \\
\text { OR }(95 \mathrm{CI})\end{array}$ \\
\hline \multicolumn{7}{|l|}{ Practice characteristics } \\
\hline \multicolumn{7}{|l|}{$\begin{array}{l}\text { Demographic: } \\
\text { 1. Solo } \\
\text { 2. Urban area }\end{array}$} \\
\hline Large city & & & $0.45(0.30-0.66)$ & $0.48(0.32-0.73)$ & $0.43(0.29-0.63)$ & $0.43(0.28-0.66)$ \\
\hline Small urban & & & $0.60(0.41-0.87)$ & $0.50(0.34-0.74)$ & $0.53(0.37-0.76)$ & $0.58(0.38-0.86)$ \\
\hline \multicolumn{7}{|l|}{ Organization: } \\
\hline $\begin{array}{l}\text { Always } \\
\text { Sometimes }\end{array}$ & & $0.75(0.58-0.98)$ & & & & \\
\hline 5. Pamphlets & & $1.54(1.12-2.11)$ & & & & \\
\hline 6. Special hours & $2.85(1.43-5.67)$ & & & $3.35(1.35-8.31)$ & & \\
\hline \multicolumn{7}{|l|}{ Patient characteristics } \\
\hline \multicolumn{7}{|l|}{ Demographic: } \\
\hline 7. Age $^{a}$ & $1.10(1.06-1.14)$ & $1.39(1.34-1.44)$ & $1.37(1.27-1.49)$ & $1.45(1.37-1.53)$ & $1.78(1.69-1.87)$ & $1.34(1.27-1.41)$ \\
\hline 8. Male & & $0.82(0.76-0.88)$ & $0.82(0.70-0.97)$ & & $0.80(0.73-0.87)$ & $0.76(0.69-0.83)$ \\
\hline $\begin{array}{l}\text { 9. Social health } \\
\text { insurance }\end{array}$ & $1.29(1.20-1.40)$ & $1.45(1.35-1.56)$ & $1.35(1.12-1.61)$ & $1.53(1.34-1.75)$ & $1.38(1.26-1.51)$ & $1.43(1.30-1.57)$ \\
\hline \multicolumn{7}{|l|}{$\begin{array}{l}\text { Additional high-risk } \\
\text { indication: }\end{array}$} \\
\hline 10. Pulmonary disease & $2.50(2.22-2.81)$ & $1.36(1.25-1.48)$ & & $1.72(1.44-2.04)$ & n.a. & n.a. \\
\hline 11. Cardiac disease & $2.10(1.92-2.30)$ & $1.53(1.37-1.70)$ & $1.50(1.21-1.85)$ & n.a. & $1.87(1.57-2.23)$ & $2.04(1.55-2.66)$ \\
\hline 12. Diabetic disease & $2.06(1.81-2.35)$ & $1.69(1.50-1.91)$ & n.a. & $1.48(1.22-1.78)$ & $1.29(1.02-1.62)$ & \\
\hline
\end{tabular}

${ }^{a}$ Mean age and comparing standard deviation of the subgroups: $65+: 74.2$ (7.0); <65: 39.4 (18.8); Diabetic disease: 64.4 (15.1); Cardiac disease: 68.3 (14.4); Pulmonary disease: 45.1 (25.2); Pulmonary disease <65: 32.5 (19.0) 